\title{
MAFA controls genes implicated in insulin biosynthesis and secretion
}

\author{
H. Wang $\cdot$ T. Brun $\cdot$ K. Kataoka $\cdot$ A. J. Sharma $\cdot$ \\ C. B. Wollheim
}

Received: 26 May 2006 / Accepted: 25 August 2006 / Published online: 6 December 2006

(C) Springer-Verlag 2006

\begin{abstract}
Aims/hypothesis Effects of the transcription factor v-maf musculoaponeurotic fibrosarcoma oncogene homologue A (MAFA) on the regulation of beta cell gene expression and function were investigated.

Materials and methods INS-1 stable cell lines permitting inducible up- or downregulation of this transcription factor were established.

Results MAFA overproduction enhanced and its dominantnegative mutant (DN-MAFA) diminished binding of the factor to the insulin promoter, correlating with insulin
\end{abstract}

Electronic supplementary material Supplementary material is available in the online version of this article at http://dx.doi.org/ $10.1007 / \mathrm{s} 00125-006-0490-2$ and is accessible to authorised users.

H. Wang $(\varangle) \cdot$ T. Brun $\cdot$ C. B. Wollheim $(\square)$

Department of Cell Physiology and Metabolism,

University Medical Center,

1, Michel-Servet,

CH-1211 Geneva 4, Switzerland

e-mail: haiyan.wang.hw2@Roche.com

e-mail: claes.wollheim@medecine.unige.ch

\section{K. Kataoka}

Laboratory of Molecular and Developmental Biology,

Graduate School of Biological Science,

Nara Institute of Science and Technology,

Takayama-cho,

Ikoma, Japan

\author{
A. J. Sharma \\ Joslin Diabetes Center, \\ Boston, MA, USA \\ Present address: \\ H. Wang \\ PRBD-Metabolic diseases, \\ Hoffmann-La Roche, \\ Basel, Switzerland
}

Section of Islet Transplantation and Cell Biology,
mRNA levels and cellular protein content. Glucose-stimulated insulin secretion was facilitated by MAFA and blunted by DN-MAFA. This is partly due to alterations in glucokinase production, the glucose sensor of beta cells. In addition, the expression of important beta cell genes, e.g. those encoding solute carrier family 2 (facilitated glucose transporter), member 2 (formerly known as GLUT2), pancreatic and duodenal homeobox factor 1 (PDX1), NK6 transcription factor-related, locus 1 (NKX6-1), glucagonlike peptide 1 receptor (GLP1R), prohormone convertase 1/3 (PCSK1) and pyruvate carboxylase (PC), was regulated positively by MAFA and negatively by DN-MAFA.

Conclusions/interpretation The data suggest that MAFA is not only a key activator of insulin transcription, but also a master regulator of genes implicated in maintaining beta cell function, in particular metabolism-secretion coupling, proinsulin processing and GLP1R signalling. Our in vitro study provides molecular targets that explain the phenotype of recently reported Mafa-null mice. We also demonstrate that MAFA is produced specifically in beta cells of human islets. Glucose influenced DNA-binding activity of MAFA in rat islets in a bell-shaped manner. MAFA thus qualifies as a master regulator of beta-cell-specific gene expression and function.

Keywords Beta cells · Human · Islet insulin secretion . MAFA $\cdot$ Metabolism

$\begin{array}{ll}\text { Abbreviations } \\ \text { DN-MAFA } & \text { dominant-negative mutant of MAFA } \\ \text { EMSA } & \text { electrophoretic mobility-shift assay } \\ \text { GCK } & \text { glucokinase } \\ \text { GLP1R } & \text { glucagon-like peptide 1 receptor } \\ \text { HADH2 } & \text { 3-hydroxyacyl-CoA dehydrogenase type II } \\ \text { HNF4 } \alpha & \text { hepatocyte nuclear factor } 4 \alpha\end{array}$


ISL1 ISL1 transcription factor LIM/homeodomain (islet-1)

KRBH KRB-HEPES buffer

MAFA V-maf musculoponeurotic fibrosarcoma oncogene homologue A

NEUROD1 neurogenic differentiation factor 1

NKX6-1 NK6 transcription factor-related, locus 1

PAX4 paired-box protein 4

PC pyruvate carboxylase

PCSK1 prohormone convertase $1 / 3$

PDX1 pancreatic and duodenal homeobox factor 1

SLC2A2 solute carrier family 2 (facilitated glucose transporter), member 2

TCF1 transcription factor 1, hepatic

TFAM transcription factor A, mitochondrial

UCP2 uncoupling protein 2 (mitochondrial, proton carrier)

\section{Introduction}

Type 1 diabetes is characterised by absolute insulin deficiency caused by autoimmune destruction of the insulin-producing pancreatic beta cells. Patients with this disease require daily injections of insulin or islet transplantation. Because islet donors are scarce, the generation of insulin-producing cells from human progenitor/stem cells has become a key challenge in the treatment of type 1 diabetes. The reduction in insulin secretory capacity and beta cell mass are the precipitating factors for development of type 2 diabetes in addition to insulin resistance in the liver, muscle and adipose tissues. Therefore, the identification and characterisation of key transcription factors regulating beta cell gene expression and insulin secretion are essential not only for treatment of type 1 diabetes but also for understanding the pathogenesis of beta cell dysfunction in type 2 diabetes.

The beta cell specificity and glucose responsiveness of insulin expression are conferred by three conserved enhancer elements in the promoter region of the insulin gene. These are E1, A3, and RIPE3b/C1, which, respectively, bind three transcription factors: neurogenic differentiation factor 1 (NEUROD1), pancreatic and duodenal homeobox factor 1 (also known as insulin promoter factor 1, homeodomain transcription factor [IPF1]) and v-maf musculoaponeurotic fibrosarcoma oncogene homologue A (MAFA) [1-5]. NEUROD1 is produced in all pancreatic endocrine cell types, whereas PDX1 and MAFA display beta-cell-restricted production [1-5]. Mouse models with targeted gene disruption have revealed the essential roles of Neurod 1 and $P d x l$ in pancreatic development and beta cell differentiation. In addition, mutations in human NEURODI and $P D X 1$ are associated, respectively, with MODY, subtypes 4 and 6 . Moreover, adenovirus vector-mediated gene therapy using either Neurodl in combination with betacellulin [6] or $P d x 1$ alone [7] has been shown to induce insulin production in mouse liver and cure streptozotocininduced diabetes. Similar gene therapy was recently shown to yield encouraging results, taking advantage of the synergistic actions of Mafa, Pdxl and Neurodl [8]. Furthermore, beta cell replacement therapy in similar animal models has been achieved using in vitro-differentiated insulin-producing cells, which are generated through expression of $P d x 1$ in human fetal liver progenitor cells [9].

Large MAF proteins represent a subgroup of the MAF family of basic-leucine zipper transcription factors and include MAFA, c-MAF, MAFB and neural retina-specific leucine zipper protein (NRL) [4, 5]. MAFA is a key regulator of insulin gene transcription, whereas c-MAF and MAFB are produced specifically in adult alpha cells and control the glucagon promoter activity [4, 10]. Recent studies, however, suggest that MAFB is not only important for islet alpha cell function, but may also be involved in regulating genes required for both alpha and beta cell differentiation during development [11-13]. It is noteworthy that reduced MAFA function has been implicated in the development of beta cell dysfunction [14-19]. Hyperglycaemia suppresses Mafa expression in vivo, which is prevented by constitutive overexpression of forkhead box O1 (Foxol) in beta cells [14]. In addition, glucotoxicity and lipotoxicity inhibit insulin expression through regulation of the DNA-binding activity and/or levels of MAFA and PDX1 [18]. Moreover, reduced expression of Mafa has been reported in beta cells deficient in both insulin and IGF-1 receptors and is associated with reduced beta cell mass and diabetes [19].

The role of MAFA in regulation of pancreatic beta cell gene expression and insulin secretion has not been fully characterised. Using inducible INS-1 beta cell models, we have previously defined the function of PDX1 in the regulation of target gene expression and insulin secretion $[20,21]$, consistent with the results obtained in mice with beta-cell-specific deletion of $P d x 1$ [22, 23]. Similar approaches were employed in the present study to establish the regulatory role of MAFA in beta cell function.

\section{Materials and methods}

Establishment of inducible INS-1 stable cell lines The firststep stable and INS-1-derived INS-rbeta (also referred to as r9) cell line, which carries the reverse tetracycline/doxycycline-dependent transactivator [24] has been described previously $[20,25]$. The plasmids used in the secondary stable transfection were constructed by subcloning the cDNA encoding either wild-type MAFA [5] or its dominant-negative mutant (DN-MAFA) [3] into the expression 
vector PUHD10-3 [24] (a generous gift from H. Bujard, University of Heidelberg, Germany). Both MAFA and DNMAFA were epitope-tagged with haemagglutinin. The procedures for stable transfection, clone selection, and screening have been described previously [25].

Cell culture The standard rat insulinoma INS-1-derived stable cell lines were cultured in RPMI 1640 containing $11.2 \mathrm{mmol} / 1$ glucose [26], unless otherwise indicated.

Immunofluorescence in INS-1 cells Cells grown on polyornithine-treated glass coverslips were treated for $24 \mathrm{~h}$ with or without $500 \mathrm{ng} / \mathrm{ml}$ doxycycline. Cells were then fixed and incubated with anti-haemagglutinin tag (a kind gift from MBL/LabForce, Nunningen, Switzerland) (1:100 dilution), followed by the second antibody labelling.

Nuclear protein extraction and electrophoretic mobility-shift assay Nuclear extracts from INS-1 cells were prepared as previously described [26]. Rat islets were isolated by collagenase digestion and their nuclear proteins were extracted as reported [26]. The double-stranded oligonucleotide corresponding to the RIPE3b/C1 element of the rat insulin II promoter, 5'-TGGAAACTGCAGCTT CAGCCCCTCTG-3', was used as a probe [4]. Electrophoretic mobility-shift assay (EMSA) procedures were performed using the same conditions for probe labelling and binding reactions as previously described [26]. Anti-MAFA antibody (Bethyl, Montgomery, TX, USA) was used for supershift experiments.

Western blotting For western blotting, cells were cultured with $0,75,150$, and $500 \mathrm{ng} / \mathrm{ml}$ doxycycline for $24 \mathrm{~h}$. Nuclear extracts and total cellular proteins were fractionated by $11 \%$ SDS-PAGE. The dilution for MAFA antibody was 1:4,000. Immunoblotting procedures were performed as described previously [26] using enhanced chemiluminescence (Pierce, Rockford, IL, USA) for detection.

Measurements of insulin secretion and cellular insulin content Insulin secretion in INS-1-derived cells was measured in 24-well plates over a period of $30 \mathrm{~min}$, in KRBHEPES buffer (KRBH; mmol/l: $140 \mathrm{NaCl}, 3.6 \mathrm{KCl}, 0.5$ $\mathrm{NaH}_{2} \mathrm{PO}_{4}, 0.5 \mathrm{MgSO}_{4}, 1.5 \mathrm{CaCl}_{2}, 2 \mathrm{NaHCO}_{3}, 10$ HEPES, $0.1 \% \mathrm{BSA}$ ) containing the indicated concentrations of glucose. Cellular insulin content was determined after extraction with acid ethanol following the procedures of Wang et al. [26]. Insulin was detected by radioimmunoassay using rat insulin as a standard [26].

Total RNA isolation and northern blotting Total RNA was extracted and blotted onto nylon membranes as described previously [25]. The membrane was prehybridised and then hybridised to ${ }^{32} \mathrm{P}$-labelled random primer cDNA probes according to Wang and Iynedijian [25]. To ensure equal RNA loading and even transfer, all membranes were stripped and re-hybridised with a house-keeping gene probe (cyclophilin). cDNA fragments used as probes for Mafa, glucokinase $(G c k)$, solute carrier family 2 (facilitated glucose transporter), member 2 (Slc2a2, formerly known as Glut2), insulin, transcription factor 1, hepatic (Tcfl, formerly known as hepatocyte nuclear factor $1 \alpha[H n f l \alpha]$ ), hepatocyte nuclear factor $4 \alpha$ (Hnf4a), NeuroDl and Pdxl mRNA detection were digested from the corresponding plasmids. cDNA probes for rat glucagon-like peptide 1 receptor (Glplr), NK6 transcription factor-related, locus 1 (Nkx6-1), glucagon, prohormone convertase 1/3 (Pcsk1), pyruvate carboxylase, uncoupling protein 2 (mitochondrial, proton carrier) (Ucp2), transcription factor $\mathrm{A}$, mitochondrial (Tfam), short-chain 3-hydroxyacyl-CoA dehydrogenase
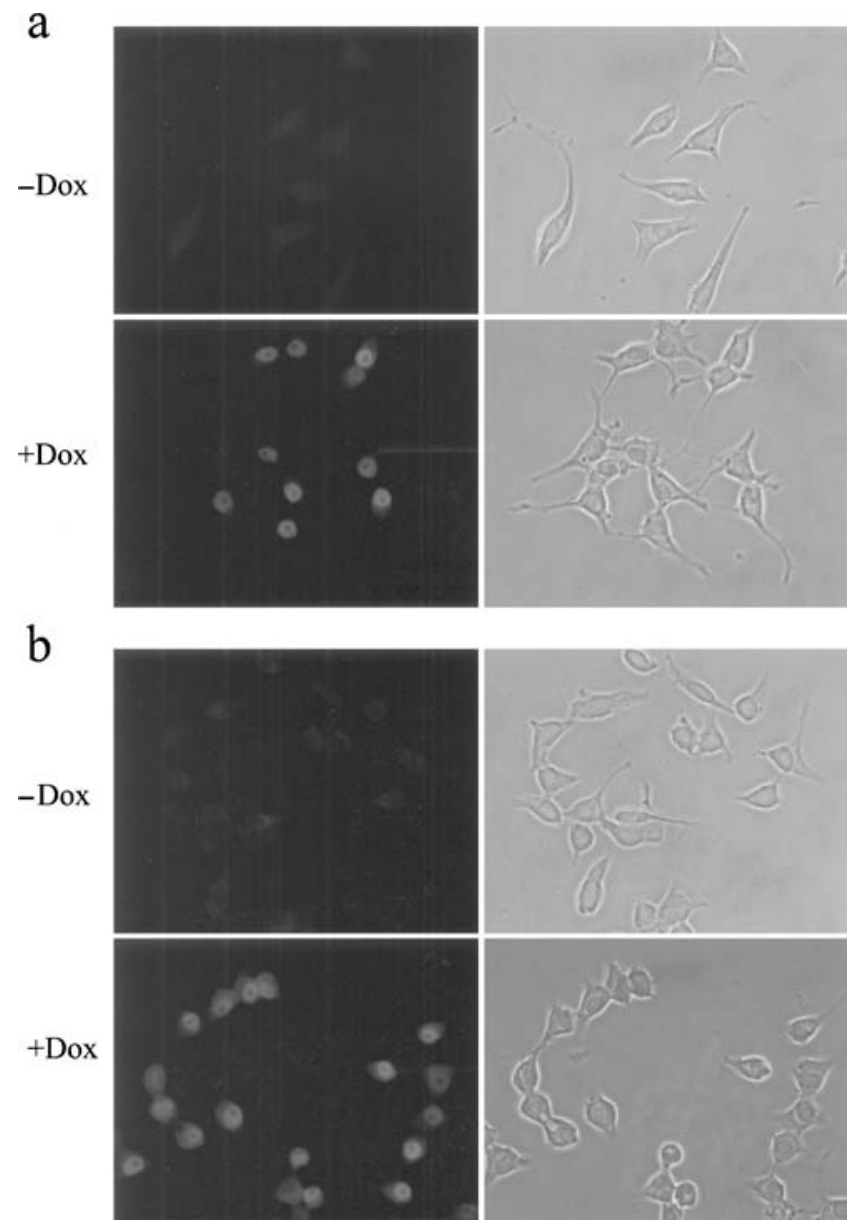

Fig. 1 Both MAFA and DN-MAFA were induced in an all-or-none manner. Immunofluorescence staining with antibody against haemagglutinin (HA)-tag showed that both MAFA (a) and DN-MAFA (b) proteins were induced by doxycycline in an all-or-none manner. The phase contrast images are shown on the right. HA-Mafa*22 (a) and HA-DN-Mafa*39 (b) cells were cultured with (+Dox) or without (-Dox) $500 \mathrm{ng} / \mathrm{ml}$ doxycycline for $24 \mathrm{~h}$ 
type II (Hadh2), acyl-CoA oxidase and cyclophilin were prepared by RT-PCR and confirmed by sequencing.

Human islet isolation and culture Freshly isolated human islets from three different donors, who had provided written informed consent, were obtained from D. Bosco (Cell Isolation and Transplantation Center, Department of Surgery, Geneva, Switzerland) and maintained in CMRL-1066 (Invitrogen) at $5.6 \mathrm{mmol} / 1$ glucose supplemented with $10 \%$ FCS, 100 Units/ml penicillin, $100 \mu \mathrm{g} / \mathrm{ml}$ streptomycin and $100 \mu \mathrm{g} / \mathrm{ml}$ gentamycin (Sigma) for 2-4 days before experiments. The present investigation was approved by the institutional ethics committee. Handpicked islets were then exposed to 5.6 or $11 \mathrm{mmol} / \mathrm{l}$ glucose with or without the GLP1R agonist exendin-4 (10 nmol/l) for $24 \mathrm{~h}$.

Immunohistochemistry After stimulation, human islets were partially dispersed by trypsin treatment and cells were fixed and incubated with primary rabbit antibodies for MAFA, ISL1 transcription factor, LIM/homeodomain, (islet-1) (ISL1) and PDX1 (dilutions 1:250) and mouse anti-insulin (1:1,000, Sigma), followed by labelling with secondary antibodies and staining with $10 \mu \mathrm{g} / \mathrm{ml} \mathrm{4',6-diamidino-2-}$ phenylindole. Images were acquired with a Zeiss Axiocam Imaging System (Bioimaging Core Facility, Medical Faculty, Geneva University, Geneva, Switzerland).

Statistics Results are expressed as mean \pm SEM and statistical analyses were performed by unpaired Student's $t$ test.

\section{Results}

Establishment of stable INS-1 cell lines permitting inducible expression of Mafa and DN-Mafa We established more than ten clones positively expressing Mafa and DN-Mafa, respectively, using parental INS-rbeta cells [20]. The clones, designated as Mafa*22 and DN-Mafa*39, were selected for the present study because they displayed robust levels of Mafa or DN-Mafa mRNAs after doxycycline induction and showed undetectable background expression under non-induced conditions.

Characterisation of INS-1 clones producing MAFA and $D N-M A F A$ Immunofluorescence with an antibody against the N-terminal epitope haemagglutinin tag illustrated that nuclear-localised MAFA (Fig. 1a) and DN-MAFA (Fig. 1b) proteins were induced in an all-or-none manner. Both Mafa*22 (Fig. 1a) and DN-Mafa*39 cells (Fig. 1b) were cultured with $500 \mathrm{ng} / \mathrm{ml}$ doxycycline for $24 \mathrm{~h}$.

Western blotting (Fig. 2a) with an antibody against the Cterminus of MAFA demonstrated that Mafa*22 cells expressed the transgene-encoded protein in a doxycycline dose-dependent manner. The protein levels of MAFA in cells cultured for $24 \mathrm{~h}$ with 75, 150 and $500 \mathrm{ng} / \mathrm{ml}$ doxycycline were approximately threefold, sixfold, and 15-fold higher than the endogenous level (Fig. 2a). As expected, the same MAFA antibody also recognised DN-MAFA, which was induced about fivefold compared with endogenous wild-type MAFA after $500 \mathrm{ng} / \mathrm{ml}$ doxycycline treatment for $24 \mathrm{~h}$ (Fig. 2a). Most importantly, DN-Mafa*39 cells did not show detectable expression of DN-MAFA protein under noninduced conditions (Fig. 2a).

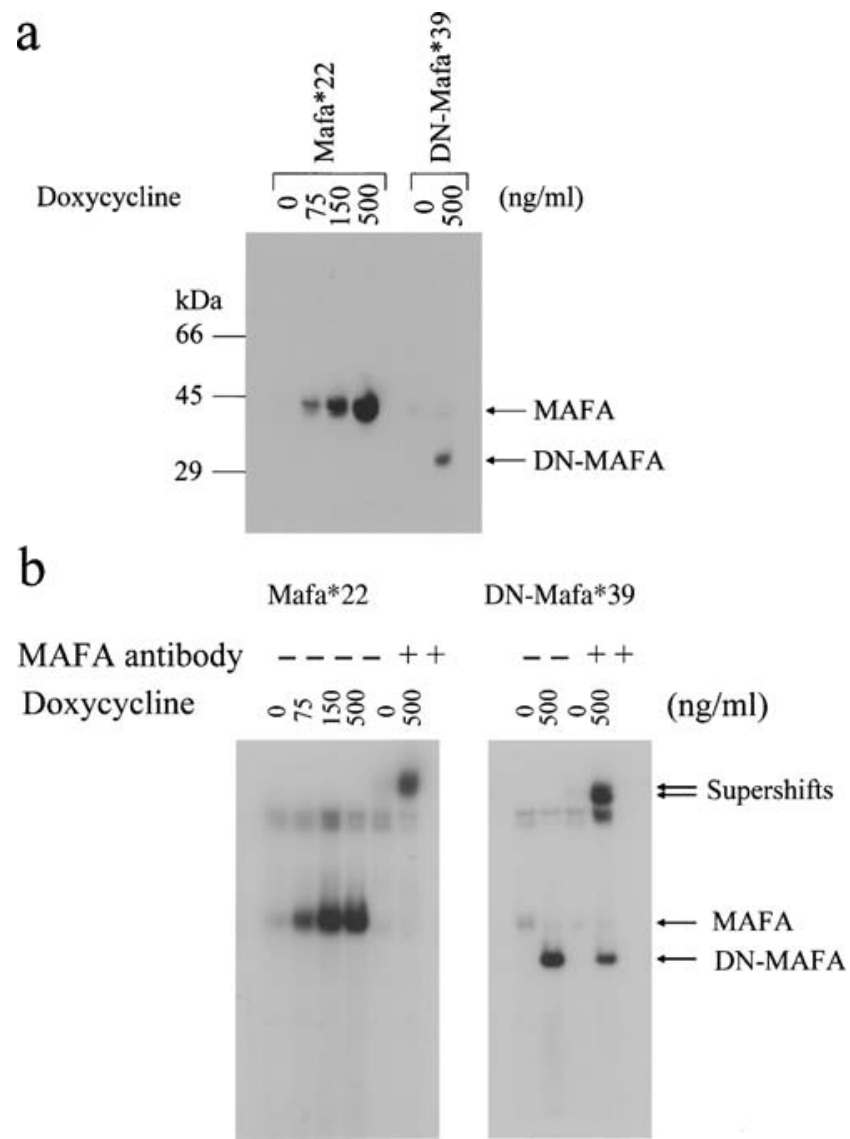

Fig. 2 MAFA binding to the insulin promoter was enhanced by induction of MAFA and diminished by DN-MAFA. a Immunoblotting with antibody against MAFA demonstrated the graded induction of MAFA protein after induction with incremental doses of doxycycline. DN-MAFA protein was induced by doxycycline in an all-or-none manner (0 and $500 \mathrm{ng} / \mathrm{ml}$ doxycycline). Nuclear proteins were extracted from Mafa*22 and DN-Mafa*39 cells induced for $24 \mathrm{~h}$ with indicated concentrations of doxycycline. b EMSA with the $\mathrm{RIPE} 3 \mathrm{~b} / \mathrm{C} 1$ element of the insulin promoter demonstrated that MAFA DNA-binding activity was incrementally increased by graded overproduction of MAFA (left) and nearly abolished by induction of DNMAFA (right). The antibody against the C-terminus of MAFA supershifted both MAFA and DN-MAFA as expected. Nuclear proteins were extracted from Mafa*22 and DN-Mafa*39 cells induced for $24 \mathrm{~h}$ with the indicated concentrations of doxycycline. Two to four independent experiments were performed with similar results 
EMSA with the RIPE3b/C1 element of the insulin promoter demonstrated that doxycycline-induced MAFA production increased its DNA-binding activity dose-dependently (Fig. 2b). The intensity of retarded MAFA binding complexes, performed with nuclear extracts from cells cultured for $24 \mathrm{~h}$ with 75,150 , and $500 \mathrm{ng} / \mathrm{ml}$ doxycycline, was estimated to be fivefold, 15- and 15-fold, respectively, compared with that of endogenous MAFA (Fig. 2b). DNMAFA lacks the N-terminal transactivation domain, but contains intact DNA-binding activity [3]. It therefore exerts its dominant-negative function through competing with endogenous MAFA for cognate DNA binding. Indeed, induction of DN-MAFA almost completely abolished MAFA DNA-binding activity (Fig. 2b). Again, no leakage binding activity of DN-MAFA was observed under noninduced conditions. The specificity of retarded binding complexes of MAFA and DN-MAFA were confirmed by the supershift experiments with MAFA antibody.

MAFA controls the expression of beta-cell-specific genes To explore the gene expression patterns regulated by MAFA, we performed quantitative northern blotting using total RNAs extracted from Mafa*22 and DN-Mafa*39 cells under induced and non-induced conditions. As shown in Fig. 3a, graded overexpression of Mafa resulted in a stepwise increase in levels of $P d x 1$ and $N k x 6-1$ mRNAs. Overexpression of Mafa approximately threefold above the endogenous level induced maximum expression of the insulin gene and Glp1r (Fig. 3a). To rule out the possibility that this observation was an artefact caused by superphysiological overexpression of Mafa, we also investigated the gene expression profile in Mafa*22 cells cultured with increasing concentrations of glucose in the presence of $75 \mathrm{ng} / \mathrm{ml}$ doxycycline (Fig. 3b). Induction of Mafa by three- to fourfold drastically increased the mRNA levels of five beta-cell-specific genes including insulin, Glplr, $P d x 1$, Nkx6-1 and Pcsk1 [22, 27-32]. GLP1R mediates the positive effects of GLP-1 on beta cell growth and insulin secretion [28], whereas PCSK1 (PC-1/3) plays a dominant role in processing of proinsulin [33]. In contrast, the expression of Tcfl, Hnf $4 a$, and Neurodl, which are ubiquitously distributed in all islet endocrine cells [34, 35], was not induced by MAFA (Fig. 3b). Interestingly, MAFA represents, to date, the most potent transcription factor in the regulation of insulin gene expression and possibly of other beta-cell-specific genes in our systematic screening of INS-1 cell models. An increase in endogenous insulin expression has never been observed in similar INS-1 cell lines expressing $P d x 1$ [20], Tcfl [26] and Hnf4a [36], as well as Neurodl and paired-box gene 4 (Pax4) (unpublished data, H. Wang and C. M. Wollheim).

Accordingly, induction of DN-MAFA led to a marked reduction in the transcript levels of insulin, Glplr, $P d x 1$, a

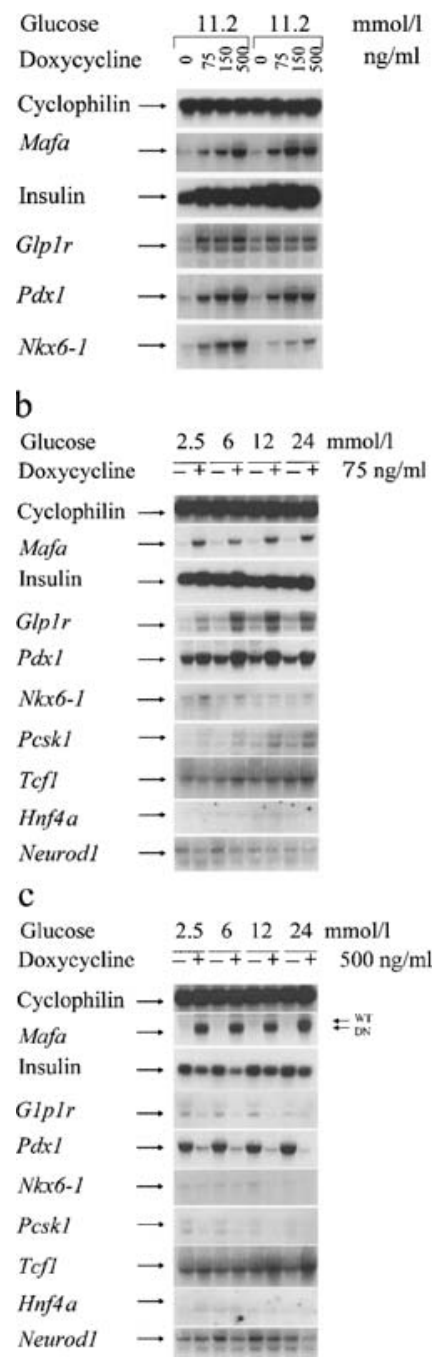

Fig. 3 MAFA targets beta-cell-specific genes. The gene expression pattern in these cells was quantitatively evaluated by northern blotting. Total RNA samples $(20 \mu \mathrm{g})$ were analysed by hybridising with the indicated cDNA probes. The experiments were repeated twice with similar results. a Mafa*22 cells were cultured in standard medium (11.2 $\mathrm{mmol} / \mathrm{l}$ glucose) with $0,75,150$ or $500 \mathrm{ng} / \mathrm{ml}$ doxycycline for $24 \mathrm{~h}$. Two independent experiments were blotted side by side to demonstrate reproducibility. At 75, 150 and $500 \mathrm{ng} / \mathrm{ml}$ doxycycline, Mafa was induced by 3.2-, 8.7- and 11.6-fold, respectively. This caused a corresponding increase in the expression of the insulin gene (by 1.8-, 1.8- and 1.5-fold), Glplr (by 2.4-, 2.2- and 2.3-fold), PdxI (3.1-, 4.7-, and 4.8-fold) and $N k x 6-1$ (2.7-, 3.1-, and 4.2-fold). Data represent the average of two experiments. b Mafa*22 cells were cultured with or without $75 \mathrm{ng} / \mathrm{ml}$ doxycycline in $2.5 \mathrm{mmol} / \mathrm{l}$ glucose medium for $16 \mathrm{~h}$, and then incubated for a further $8 \mathrm{~h}$ at the indicated glucose concentrations. The 3.4-fold induction of Mafa resulted in increased expression of the insulin gene (by 1.9-fold), Glp1r (by 3.2-fold), $P d x 1$ (by 4.1 -fold) and $N k x 6-1$ (by 2.3-fold). Data represent the average of experiments at four glucose concentrations. c DN-Mafa*39 cells were cultured with or without $500 \mathrm{ng} / \mathrm{ml}$ doxycycline in $2.5 \mathrm{mmol} / 1$ glucose medium for $16 \mathrm{~h}$, and then incubated for a further $8 \mathrm{~h}$ at the indicated glucose concentrations. Induction of DN-Mafa led to decreased mRNA levels of insulin (by 62\%), Glp1r (by 74\%), $P d x 1$ (by 91\%), Nkx6-1 (by $31 \%$ ) and Pcskl (by 52\%). Data represent the average at the four glucose concentrations 
Nkx6-1 and Pcskl, whereas the expression of Tcf1 and Hnf4a was unaltered (Fig. 3c). However, Neurodl expression was suppressed by DN-MAFA (Fig. 3c).

We and others have previously shown that PDX1 and NKX6-1 suppress glucagon expression, causing a shift from an alpha to a beta phenotype $[20,31]$. We therefore examined whether MAFA has a similar function. Unexpectedly, induction of MAFA did not inhibit the expression of glucagon, as demonstrated by northern blotting after prolonged film exposure (Electronic supplementary material [ESM] Fig. 1). More intriguingly, induction of DNMAFA diminished levels of glucagon mRNA (ESM Fig. 1), an effect opposite to that observed in response to suppression of PDX1 or NKX6-1 activity in INS-1 cells. Therefore, the effects of MAFA cannot be simply explained as functioning through PDX1 or NKX6-1.

MAFA regulates the expression of genes implicated in glucose metabolism We investigated further the effects of MAFA on other beta-cell-specific genes involved in glucose metabolism. Using quantitative northern blotting analysis we found that overexpression of Mafa robustly up-regulated the expression of two beta-cell-restricted genes, namely Slc2a2 and $P_{c}$ (Fig. 4a,b). In addition, dominant-negative suppression of Mafa drastically downregulated transcript levels of these two genes (Fig. 4c). SLC2A2 is the major glucose transporter expressed in rodent beta cells [37], while pyruvate carboxylase participates in the regulation of metabolism-secretion coupling in beta cells $[38,39]$.

Although Gck is expressed in both islet alpha and beta cells, it has been shown to confer beta cell glucose-sensing $[25,40]$. The mRNA levels of Gck were elevated by MAFA and reduced by DN-MAFA (Fig. 4). Such effects seem to be unique to MAFA, since Gck expression remained constant in our INS-1 cells permitting either induction or dominant-negative suppression of other pancreatic transcription factors, such as PDX1 [20], TCF1 [26], and HNF $4 \alpha$ [36], as well as NEUROD1 or PAX4 (unpublished data, H. Wang and C. M. Wollheim).

The expression of other genes encoding proteins implicated in metabolism-secretion coupling, such as UCP2, TFAM, HADH2, and acyl-CoA oxidase [41-43], was not regulated by manipulation of MAFA function in INS-1 cells (Fig. 4). UCP2 and TFAM modulate, respectively, the membrane potential and biogenesis of mitochondria, whereas HADH2 and acyl-CoA oxidase are involved in fatty acid metabolism.

MAFA regulates glucose-stimulated insulin secretion The effects of MAFA on the expression of $G c k$ and $P c$ as well as $S l c 2 a 2$ suggest that MAFA could be implicated in the regulation of metabolism-secretion coupling in beta cells. We therefore examined the impact of induction or domi- a

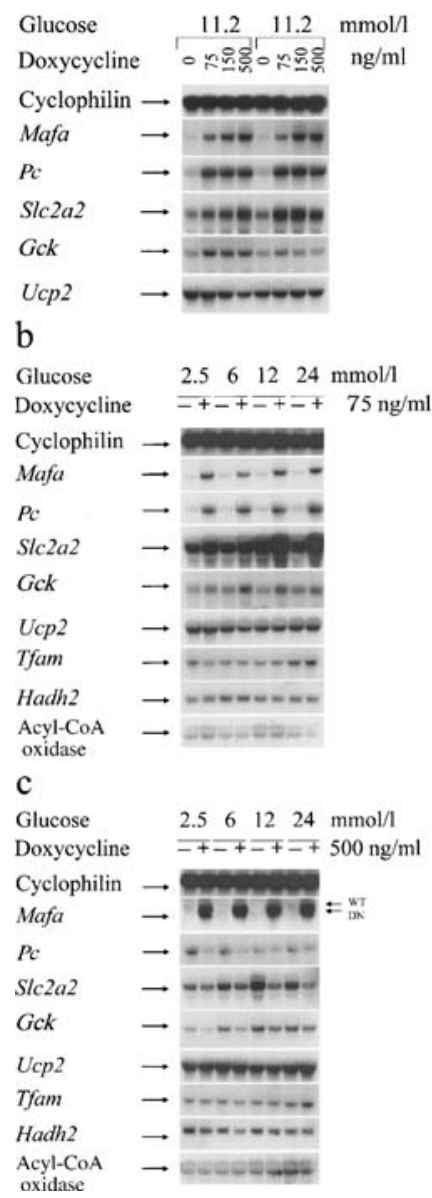

Fig. 4 MAFA targets genes essential for metabolism-secretion coupling. Total RNA samples $(20 \mu \mathrm{g})$ were analysed by hybridising with indicated cDNA probes. The experiments were repeated twice with similar results. a Mafa*22 cells were cultured as described in Fig. 3a. Two separate experiments were blotted side by side to demonstrate consistency. Mafa was induced 3.4-, 8.3- and 10.2-fold by 75,150 and $500 \mathrm{ng} / \mathrm{ml}$ doxycycline, respectively. This resulted in corresponding increases in the mRNA levels of $P c$ (by 4.4-, 4.8- and 4.5-fold), Slc2a2 (by 3.1-, 3.7- and 3.3-fold), and Gck (by 2.2-, 2.1and 1.8 -fold). Data represent the average of two experiments. b Mafa*22 cells were cultured as described in Fig. 3b. A 3.6-fold induction of Mafa caused increased expression of Pc, Slc2a2 and Gck by $4.3-, 2.4-$ and 1.9-fold, respectively. Data represent the average at four glucose concentrations. c DN-Mafa*39 cells were cultured as described in Fig. 3c. The gene expression pattern in these cells was quantitatively evaluated by northern blotting. Equilibration with $2.5 \mathrm{mmol} / \mathrm{l}$ glucose is necessary to observe glucose-responsive gene expression, such as Slc2a2. Induction of DN-MAFA led to decreased expression of $P c, S l c 2 a 2$ and $G c k$ by 62,46 and $37 \%$, respectively. Data represent the average at the four glucose concentrations. WT, wild-type

nant-negative suppression of MAFA on insulin secretion in INS-1 cells. As shown in Fig. 5a, overexpression of Mafa caused a shift to the left in insulin secretion in response to glucose. The MAFA-induced increase in Gck expression (Fig. 4a,b) should, at least in part, explain the left shift in glucose responsiveness, because similar results have been 
obtained in INS-1 cells overexpressing Gck [25], the ratelimiting enzyme for beta cell glucose metabolism. In contrast, dominant-negative suppression of MAFA function led to blunted glucose-induced insulin secretion, whereas insulin release elicited by $\mathrm{KCl}$ depolarisation remained constant (Fig. 5b). These results suggest that MAFA regulates metabolism-secretion coupling in steps upstream of exocytosis. INS-1 cells represent a unique model to assess the implications of pyruvate carboxylase in metabolism-secretion coupling, because these insulinoma cells produce low levels of monocarboxylate transporter, but sufficient to use pyruvate as secretogue $[44,45]$, in contrast to native islet beta cells. We therefore evaluated the consequences of DN-MAFA on pyruvate-
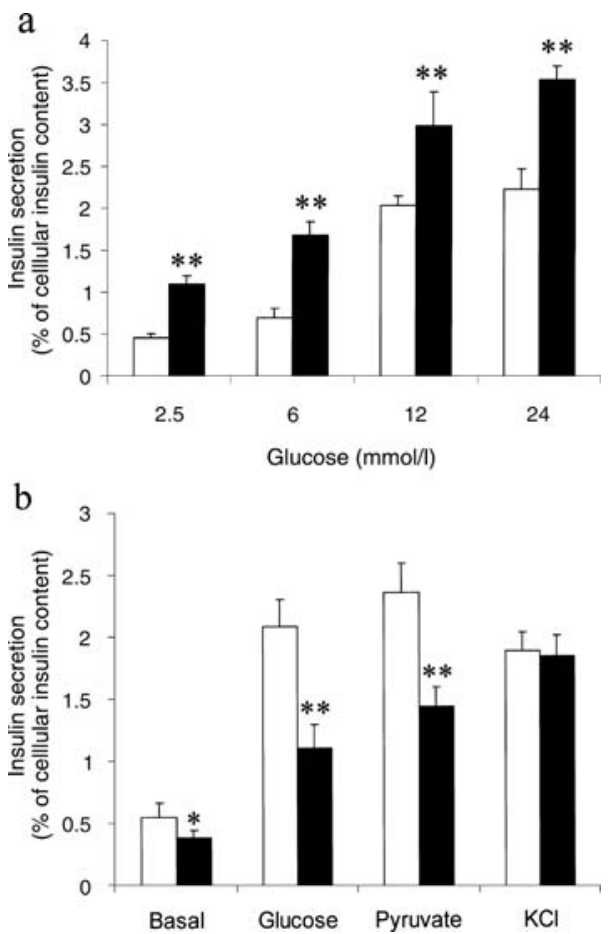

Fig. 5 MAFA regulates nutrient-stimulated insulin secretion. a Mafa*22 cells were cultured in standard medium $(11.2 \mathrm{mmol} / 1$ glucose $)$ with (dark bars) or without (open bars) $75 \mathrm{ng} / \mathrm{ml}$ doxycycline (Dox) for $19 \mathrm{~h}$, and then equilibrated in $2.5 \mathrm{mmol} / 1$ glucose medium for a further $5 \mathrm{~h}$. Insulin release from Mafa*22 cells in KRBH buffer containing the indicated concentrations of glucose was determined by radio-immunoassay and expressed as percentage of cellular insulin content. Cellular insulin content was increased by $23 \%$ (-Dox: $2.16 \pm 0.23 \mu \mathrm{g} / \mathrm{mg}$ protein; +Dox: $2.65 \pm 0.25 \mu \mathrm{g} / \mathrm{mg}$ protein, $n=6, p<0.01)$ after MAFA induction. b DN-Mafa*39 cells were cultured in standard medium $(11.2 \mathrm{mmol} / \mathrm{l}$ glucose) with (dark bars) or without (open bars) $500 \mathrm{ng} / \mathrm{ml}$ doxycycline for $19 \mathrm{~h}$, and then equilibrated in $2.5 \mathrm{mmol} / 1$ glucose medium for a further $5 \mathrm{~h}$. Induction of DN-MAFA resulted in defective insulin release induced by $24 \mathrm{mmol} / \mathrm{l}$ glucose, $5 \mathrm{mmol} / \mathrm{l}$ pyruvate, and $20 \mathrm{mmol} / \mathrm{l} \mathrm{KCl}$. Insulin secretion from DN-Mafa*39 cells stimulated by $24 \mathrm{mmol} / \mathrm{l}$ glucose, $5 \mathrm{mmol} / \mathrm{l}$ pyruvate, and $20 \mathrm{mmol} / 1 \mathrm{KCl}$ was measured in $\mathrm{KRBH}$ containing $2.5 \mathrm{mmol} / 1$ glucose (Basal) and is expressed as percentage of cellular insulin content. Cellular insulin content was reduced by $27 \%$ (-Dox: $2.245 \pm 0.22$; +Dox: $1.64 \pm 0.20 \mu \mathrm{g} / \mathrm{mg}$ protein, $n=6, p<0.005$ ). Data represent mean \pm SEM of six independent experiments. ${ }^{*} p<0.05$, $* * p<0.001$ stimulated insulin secretion in INS-1 cells. As demonstrated in Fig. 5b, induction of DN-MAFA also impaired insulin secretion in response to pyruvate, which could be explained by markedly reduced pyruvate carboxylase production (Fig. 4c). The insulin secretion data were expressed as percentage of cellular insulin, because induction of MAFA and DN-MAFA resulted in a $23 \%$ increase and $27 \%$ decrease, respectively, in the cellular insulin content.

MAFA is expressed specifically in beta cells of human islets. To characterise MAFA production in adult human islets, we performed immunofluorescence staining with antibodies against ISL1, MAFA, PDX1 and insulin. As shown in Fig. 6a, MAFA is specifically localised in nuclei of insulin-positive cells, whereas ISL1 is stained in both beta and non-beta cells. PDX1 is also almost exclusively localised in nuclei of beta cells (Fig. 6a). In addition, subcellular distribution of MAFA was not strikingly different in human islets cultured for $24 \mathrm{~h}$ in 5 and $11.2 \mathrm{mmol} / \mathrm{l}$ glucose, respectively (Fig. $6 \mathrm{~b}$ ). The negative effects of the GLP1R agonist, exendin-4, were pronounced (Fig. 6b). Since immunostaining is semi-quantitative, small changes in protein levels may not be obvious. We therefore performed EMSA to evaluate the glucose-responsiveness of DNA binding by MAFA.

Glucose regulates MAFA DNA-binding activity in rat islets Findings on glucose-regulation of MAFA have been very confusing [5, 14, 15, 46]. Zhao and colleagues [46] reported that both MAFA protein levels and its binding to the RIPE3b/C1 element are markedly increased in rat islets cultured for $24 \mathrm{~h}$ with $16.7 \mathrm{mmol} / 1$ glucose, in comparison with control islets treated with $2.8 \mathrm{mmol} / 1$ glucose. Similar glucose-induced MAFA DNA-binding activity was demonstrated in insulinoma MIN6 and $\beta$-TC6 cells [5]. In contrast, reduced MAFA DNA-binding activity and MAFA levels have been shown in INS-1 cells cultured with $16.7 \mathrm{mmol} / \mathrm{l}$ glucose for $48 \mathrm{~h}$ [17] and in HIT-T15 cells treated chronically with $11.1 \mathrm{mmol} / \mathrm{l}$ glucose [16]. To clarify this, we performed EMSA with nuclear extracts from rat islets cultured with $2.5,5,15$ and $30 \mathrm{mmol} / 1$ glucose for $48 \mathrm{~h}$. As shown in Fig. 7, MAFA DNA binding is regulated by glucose in a bell-shaped manner. The DNAbinding activity was incrementally increased in the range $2.5-15 \mathrm{mmol} / \mathrm{l}$ glucose, but reduced at $30 \mathrm{mmol} / \mathrm{l}$ glucose. These results not only support the notion that glucose enhances MAFA DNA binding [5, 46], but are also in agreement with the previous finding that glucotoxicity diminishes the DNA-binding activity [14, 16, 17]. The discrepancy between the studies in rat islets and insulinoma cells could be related to decreased sensitivity of the former to high glucose. 


\section{Discussion}

Using two INS-1 stable cell lines permitting inducible overexpression or dominant-negative suppression of MAFA, we assessed the effects of MAFA on insulin secretion. Overproduction of MAFA caused a left shift of insulin secretion in response to glucose, whereas induction of DN-MAFA blunted nutrient-stimulated insulin release.
This was not due to alterations in insulin content, since the data were expressed as percentage of cellular insulin. Recently, Zhang and colleagues [47] reported that mice deficient in MAFA developed diabetes due to impaired insulin secretion. However, the authors did not define the molecular targets responsible for the phenotype. We have defined the target genes of MAFA through quantitative gene expression profiling of our novel INS-1 cell lines
Fig. 6 MAFA is localised specifically in beta cells of human islets. a Immunofluorescent detection of the islet transcription factors ISL1, IPF1 or MAFA (green), and insulin (red), as well as 4',6-diamidino2-phenylindole (DAPI) nuclei staining (blue) in dispersed human islet cells cultured at $11.2 \mathrm{mmol} / 1$ glucose for $24 \mathrm{~h}$. Similar to IPF1, MAFA is exclusively detected in the nuclei of insulin-positive cells. b Immunocytochemical detection of MAFA (green) and beta cells (insulin in red) was performed $24 \mathrm{~h}$ after incubation with the indicated concentrations of glucose $(G l c)$ with or without the GLP1R agonist exendin-4 (ex-4, $10 \mathrm{nmol} / \mathrm{l})$. The merge image of the MAFA- and insulinproducing beta cells is shown a

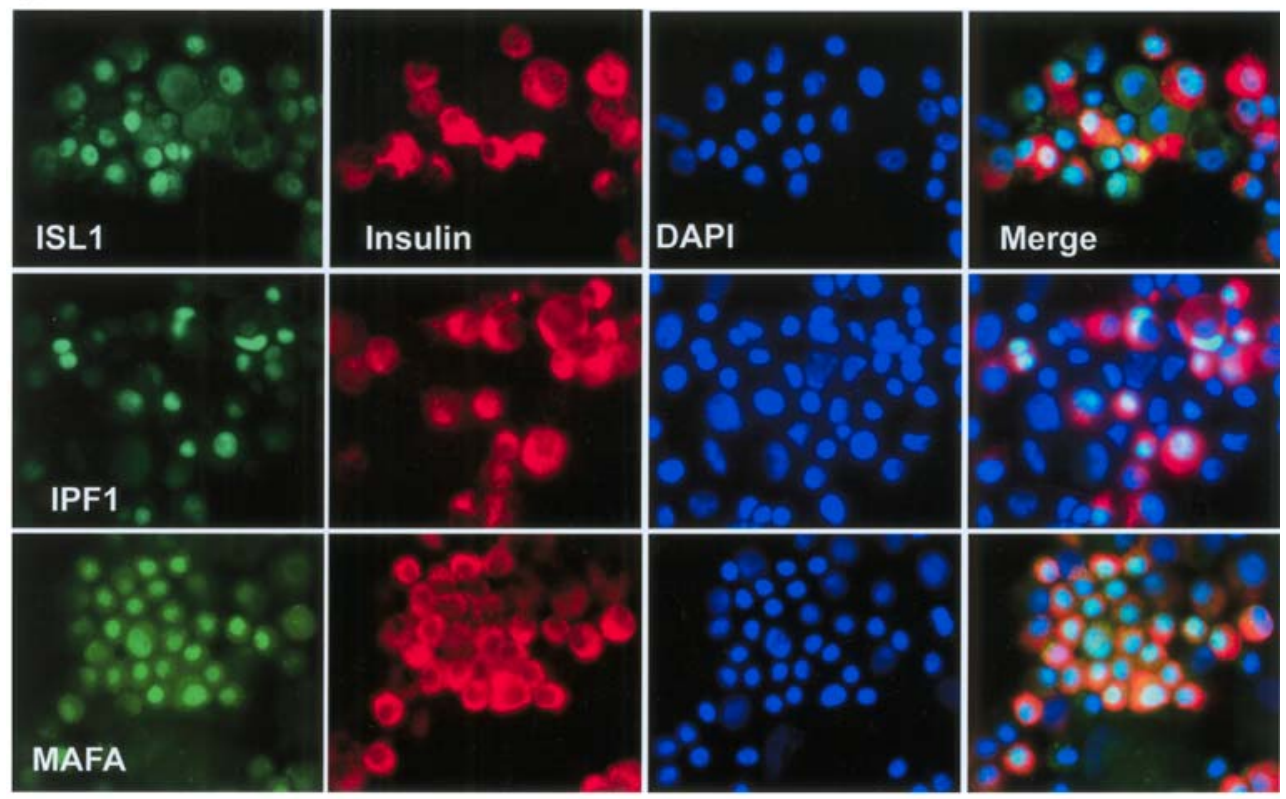

b

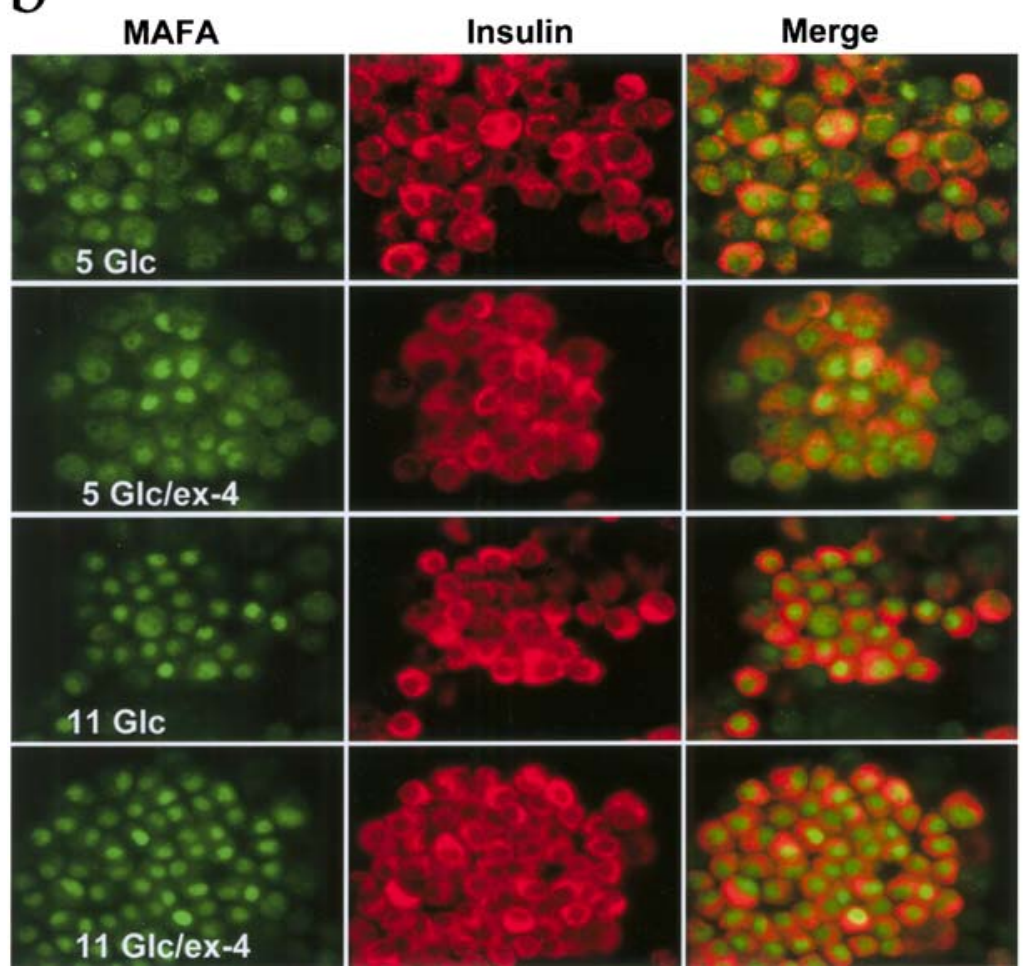




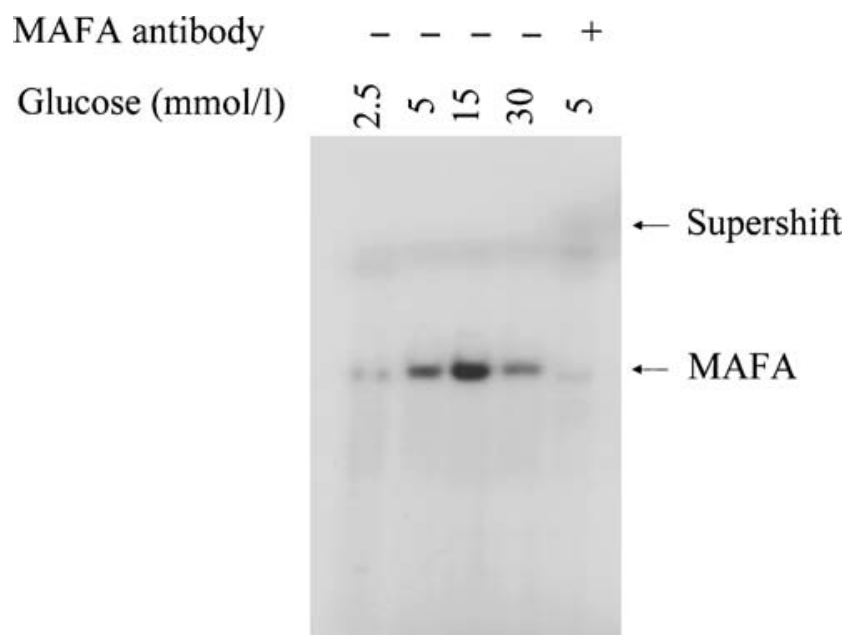

Fig. 7 Bell-shaped DNA-binding of MAFA in response to glucose was demonstrated in rat islets. EMSA was performed using the $\mathrm{RIPE} 3 \mathrm{~b} / \mathrm{C} 1$ element of the insulin promoter. Nuclear proteins were extracted from rat islets cultured with $2.5,5,15$ and $30 \mathrm{mmol} / 1$ glucose for $48 \mathrm{~h}$. DNA-binding activity was increased by $3.3 \pm 0.7,12.1 \pm 2.5$, and $2.2 \pm 0.4$-fold $(n=3)$ at 5,15 , and $30 \mathrm{mmol} / 1$ glucose concentrations, respectively. Data were calculated by scanning three independent EMSA experiments using rat islets from two separate isolations

under induced and non-induced conditions. The results demonstrate that MAFA is not only a key activator of insulin transcription, but also a master regulator of many beta cell genes implicated in maintaining beta cell phenotype, metabolism-secretion coupling, proinsulin processing and GLP1R signalling.

Overexpression of Mafa alone is sufficient to raise endogenous insulin mRNA levels. This is unique to MAFA, because induction of PDX1 [20] or NEUROD1, either separately or combined in the similar INS-1 cell system (unpublished data, H. Wang and C. B. Wollheim), did not reproduce the effects of MAFA. Similarly, other key beta cell transcription factors such as TCF 1 and $\mathrm{HNF} 4 \alpha$, as well as PAX4, do not show such potency in our systematic series of INS-1 cell models [26, 36]. Transduction of MAFA has been shown to increase endogenous insulin transcript expression in rat islets [46]. We therefore propose that MAFA could be a potent and target transcription factor employed for beta cell generation either through in vivo gene therapy or in vitro differentiation of stem/progenitor cells.

Accordingly, dominant-negative suppression of MAFA function decreased insulin production as revealed by mRNA and protein contents. We have also identified the beta-cell-enriched PCSK1and GLP1R as two novel targets of MAFA. DN-MAFA drastically suppressed the expression of Pcsk1 and Glp1r, whereas induction of MAFA enhanced their transcript levels. PCSK1 is required for insulin maturation [33], whereas GLP1R is necessary for GLP1mediated beta cell growth and insulin secretion [28]. A similar reduction of PCSK1 and GLP1R levels has also been observed in our INS- 1 cells expressing DN-Pdxl, which causes defective proinsulin processing and GLP1R signalling [21]. MAFA has been previously reported to bind the $P d x 1$ promoter [48]. Indeed, we found that PDX1 is robustly up- or downregulated following induction and suppression of MAFA function. Decreased expression of $P d x 1$ has also been demonstrated in MAFA-deficient islets [47]. We therefore postulate that MAFA regulates expression of Pcsk1 and Glp1r, at least in part by acting through PDX1.

In addition, we have also identified two other common target genes of MAFA and PDX1: Slc2a2 and Nkx6-1. Like PDX1, MAFA also controls the expression of these two beta-cell-restricted genes. Decreased levels of SLC2A2 have also been reported in the islets of Mafa-null mice [47]. However, this does not explain the impaired insulin secretion [47]. As the capacity of this hexose transporter is much greater than the activity of GCK and other glycolytic enzymes, this decrease would not affect glucose metabolism [37]. To delineate the molecular targets responsible for the regulatory effects of MAFA on insulin secretion, we evaluated the expression patterns of genes involved in metabolism-secretion coupling with or without induction of MAFA or DN-MAFA. The beta-cell-enriched PC has been identified as another novel target of MAFA in the present study. PC plays an essential role in metabolism-secretion coupling in both native beta cells and insulinoma cells [38, 39]. Approximately $50 \%$ of glucose-derived pyruvate enters mitochondrial metabolism via carboxylation catalysed by PC, while the remainder is converted into acetyl CoA by the pyruvate dehydrogenase complex [38]. This provides anaplerotic input into the tricarboxylic acid cycle [49]. INS-1 cells, which express low levels of monocarboxylate transporter that are nonetheless sufficient to take up pyruvate, provide a suitable model to assess the impact of decreased PC production on insulin secretion. Induction of DN-MAFA not only impaired glucose-stimulated but also pyruvate-induced insulin release. As pyruvate is metabolised exclusively by the mitochondria, the downregulation of PC certainly contributes, together with GCK, to the insulin secretory defect. On the other hand, the MAFA-evoked overproduction of PC may partially contribute to the left shift of insulin secretion in response to glucose. However, the beta cell glucose-sensor, GCK, should be the major player, since a similar left shift of insulin secretory response has been documented in INS-1 cells overproducing GCK [25]. At variance with Mafa-deficient mice, we found that mRNA levels of Gck were regulated positively by MAFA and negatively by DN-MAFA. This is also unique to MAFA because Gck expression remains constant in our INS-1 stable cell lines allowing induction or suppression of other pancreatic transcription factors, including PDX1 [20], TCF1 [26], HNF4 $\alpha$ [36], NEUROD1 
or PAX4 (unpublished data, H. Wang and C. B. Wollheim). The reason for the apparent difference in GCK regulation in Mafa-mutant mice and INS-1 cells is not clear. Moreover, $\mathrm{K}^{+}$-induced insulin secretion was inhibited in islets from Mafa-/- mice but not affected in INS-1 cells with suppressed MAFA function. This could be due to effects on L-type voltage-gated $\mathrm{Ca}^{2+}$ channels in native beta cells. INS-1 cells express a broader spectrum of such $\mathrm{Ca}^{2+}$ channels than native beta cells [50], which may explain the preserved insulin secretion following membrane depolarisation.

Another intriguing result with MAFA is that it does not promote the alpha to beta phenotype shift observed with PDX1 and NKX6-1 [20, 31], although our data suggest that MAFA regulates their production. We have previously shown that PDX1 suppresses glucagon production and regulates the alpha/beta phenotype shift in INS-1 cells [20]. A recent elegant study in INS-1-derived cells suggests that PDX1 acts through NKX6-1 [31]. Therefore, the effects of MAFA on beta-cell-specific gene expression cannot be explained simply by an action on PDX1. Another argument supporting this notion is that overexpression of $P d x 1$ does not potentiate glucose-stimulated insulin secretion [21]. Furthermore, in agreement with findings in Mafa-null mice [46], induction of DN-MAFA diminished the expression of Neurod1 in INS-1 cells, although MAFA induction did not affect its transcript levels.

We also demonstrated that MAFA is specifically expressed in the beta cells of human islets and that its subcellular distribution is not clearly regulated by physiological concentrations of glucose. However, the DNA-binding activity of MAFA is indeed regulated in a bell-shape manner that is dependent on glucose concentration. We therefore clarified the apparent controversies in the literature regarding the glucose responsiveness of MAFA DNA binding [5, 16, 17, 46]. To summarise data from the present study and previous reports, we suggest that glucose induces MAFA DNA-binding activity at physiological concentrations, but suppresses the binding at both sub- and supra-physiological levels.

In conclusion, we employed an inducible INS-1 cell system, which allows direct assessment of MAFA target genes. We have demonstrated that MAFA controls many beta-cell-specific genes, including insulin, Slc2a2, $P d x 1$, Nkx6-1, Glp1r, Pcsk1 and Pc. PC in combination with GCK may represent the molecular targets responsible for the regulatory effects of MAFA on metabolism-secretion coupling. Furthermore, MAFA regulates expression of genes essential for insulin transcription and processing, as well as for GLP1R signalling. Therefore, we propose that $M A F A$ is a candidate gene for diabetes and a target gene for restoring beta cell function in type 2 diabetes. In addition, it is also a potential target for treatment of type 1 diabetes through MAFA-mediated in vitro beta cell generation from progenitor/stem cells or in vivo gene therapy.
Acknowledgements We are grateful to D. Cornut-Harry, D. Nappey, and N. Aebischer for expert technical assistance. We are indebted to $\mathrm{H}$. Bujard (for the PUHD 10-3 vector), and N. Quintrell (for the pTKhygro plasmid). This work was supported by the Swiss National Science Foundation (grant no. 32-66907.01 to C. B. Wollheim), by NIH/ NIDDK RO1 DK06127 grant (to A. J. Sharma), by the Olga Mayenfisch Foundation (funding to C. B. Wollheim), and by the Roche Research Foundation, Basel. We are grateful to D. Bosco for providing human islets. This study was supported by the European Union (Integrated Project EuroDia.

LSHM-CT-2006-518153 in the Framework Programme 6 [FP6] of the European Community).

Duality of interest The authors have declared that they have no conflicts of interest.

\section{References}

1. Naya FJ, Stellrecht CM, Tsai MJ (1995) Tissue-specific regulation of the insulin gene by a novel basic helix-loop-helix transcription factor. Genes Dev 9:1009-1019

2. Ohlsson H, Karlsson K, Edlund T (1993) IPF1, a homeodomaincontaining transactivator of the insulin gene. EMBO J 12:42514259

3. Olbrot M, Rud J, Moss LG, Sharma A (2002) Identification of beta-cell-specific insulin gene transcription factor RIPE3b1 as mammalian MafA. Proc Natl Acad Sci USA 99:6737-6742

4. Matsuoka TA, Zhao L, Artner I et al (2003) Members of the large Maf transcription family regulate insulin gene transcription in islet beta cells. Mol Cell Biol 23:6049-6062

5. Kataoka K, Han SI, Shioda S, Hirai M, Nishizawa M, Handa $H$ (2002) MafA is a glucose-regulated and pancreatic beta-cellspecific transcriptional activator for the insulin gene. J Biol Chem 277:49903-49910

6. Kojima H, Fujimiya M, Matsumura K et al (2003) NeuroDbetacellulin gene therapy induces islet neogenesis in the liver and reverses diabetes in mice. Nat Med 9:596-603

7. Ferber S, Halkin A, Cohen $\mathrm{H}$ et al (2000) Pancreatic and duodenal homeobox gene 1 induces expression of insulin genes in liver and ameliorates streptozotocin-induced hyperglycemia. Nat Med 6:568-572

8. Kaneto H, Matsuoka TA, Nakatani Y et al (2005) A crucial role of MafA as a novel therapeutic target for diabetes. J Biol Chem 280:15047-15052

9. Zalzman M, Gupta S, Giri RK et al (2003) Reversal of hyperglycemia in mice by using human expandable insulinproducing cells differentiated from fetal liver progenitor cells. Proc Natl Acad Sci USA 100:7253-7258

10. Kataoka K, Shioda S, Ando K, Sakagami K, Handa H, Yasuda K (2004) Differentially expressed Maf family transcription factors, c-Maf and MafA, activate glucagon and insulin gene expression in pancreatic islet alpha- and beta-cells. J Mol Endocrinol 32:9-20

11. Artner I, Le Lay J, Hang Y et al (2006) MafB: an activator of the glucagon gene expressed in developing islet alpha- and beta-cells. Diabetes 55:297-304

12. Nishimura W, Kondo T, Salameh $\mathrm{T}$ et al (2006) A switch from MafB to MafA expression accompanies differentiation to pancreatic beta-cells. Dev Biol 293:526-539

13. Tsuchiya M, Taniguchi S, Yasuda K et al (2006) Potential roles of large mafs in cell lineages and developing pancreas. Pancreas $32: 408-416$ 
14. Kitamura YI, Kitamura T, Kruse JP et al (2005) FoxO1 protects against pancreatic beta cell failure through NeuroD and MafA induction. Cell Metab 2:153-163

15. Hagman DK, Hays LB, Parazzoli SD, Poitout V (2005) Palmitate inhibits insulin gene expression by altering PDX-1 nuclear localization and reducing MafA expression in isolated rat islets of Langerhans. J Biol Chem 280:32413-32418

16. Harmon JS, Stein R, Robertson RP (2005) Oxidative stressmediated, post-translational loss of MafA protein as a contributing mechanism to loss of insulin gene expression in glucotoxic beta cells. J Biol Chem 280:11107-11113

17. Pino MF, Ye DZ, Linning KD et al (2005) Elevated glucose attenuates human insulin gene promoter activity in INS-1 pancreatic beta-cells via reduced nuclear factor binding to the A5/core and Z element. Mol Endocrinol 19:1343-1360

18. Poitout V, Hagman D, Stein R, Artner I, Robertson RP, Harmon JS (2006) Regulation of the insulin gene by glucose and fatty acids. J Nutr 136:873-876

19. Ueki K, Okada T, Hu J et al (2006) Total insulin and IGF-I resistance in pancreatic beta cells causes overt diabetes. Nat Genet 38:583-588

20. Wang H, Maechler P, Ritz-Laser B et al (2001) Pdx1 level defines pancreatic gene expression pattern and cell lineage differentiation. J Biol Chem 276:25279-25286

21. Wang H, Iezzi M, Theander S et al (2005) Suppression of Pdx-1 perturbs proinsulin processing, insulin secretion and GLP-1 signalling in INS-1 cells. Diabetologia 48:720-731

22. Ahlgren U, Johnson J, Johnson L, Simu K, Edlund H (1998) Betacell-specific inactivation of the mouse $I p f 1 / P d x 1$ gene results in loss of the beta-cell phenotype and maturity onset diabetes. Genes Dev 12:1763-1768

23. Li Y, Cao X, Li LX, Brubaker PL, Edlund H, Drucker DJ (2005) Beta-cell Pdx1 expression is essential for the glucoregulatory, proliferative, and cytoprotective actions of glucagon-like peptide1. Diabetes 54:482-491

24. Gossen M, Freundlieb S, Bender G, Muller G, Hillen W, Bujard H (1995) Transcriptional activation by tetracyclines in mammalian cells. Science 268:1766-1769

25. Wang H, Iynedjian PB (1997) Modulation of glucose responsiveness of insulinoma beta-cells by graded overexpression of glucokinase. Proc Natl Acad Sci USA 94:4372-4377

26. Wang H, Maechler P, Hagenfeldt KA, Wollheim CB (1998) Dominant-negative suppression of HNF-1alpha function results in defective insulin gene transcription and impaired metabolismsecretion coupling in a pancreatic beta-cell line. EMBO J 17: $6701-6713$

27. Zhu X, Zhou A, Dey A et al (2002) Disruption of PC1/3 expression in mice causes dwarfism and multiple neuroendocrine peptide processing defects. Proc Natl Acad Sci USA 99:1029310298

28. Preitner F, Ibberson M, Franklin I et al (2004) Gluco-incretins control insulin secretion at multiple levels as revealed in mice lacking GLP-1 and GIP receptors. J Clin Invest 113:635-645

29. Mirmira RG, Watada H, German MS (2000) Beta-cell differentiation factor Nkx6-1 contains distinct DNA binding interference and transcriptional repression domains. J Biol Chem 275:14743-14751

30. Watada H, Mirmira RG, Leung J, German MS (2000) Transcriptional and transcriptional regulation of beta-cell differentiation factor Nkx6-1. J Biol Chem 275:34224-34230

31. Schisler JC, Jensen PB, Taylor DG et al (2005) The Nkx6-1 homeodomain transcription factor suppresses glucagon expression and regulates glucose-stimulated insulin secretion in islet beta cells. Proc Natl Acad Sci USA 102:7297-7302

32. Iype T, Francis J, Garmey JC et al (2005) Mechanism of insulin gene regulation by the pancreatic transcription factor Pdx-1: application of pre-mrna analysis and chromatin immunoprecipita- tion to assess formation of functional transcriptional complexes. J Biol Chem 280:16798-16807

33. Zhu X, Orci L, Carroll R, Norrbom C, Ravazzola M, Steiner DF (2002) Severe block in processing of proinsulin to insulin accompanied by elevation of des-64,65 proinsulin intermediates in islets of mice lacking prohormone convertase 1/3. Proc Natl Acad Sci USA 99:10299-10304

34. Naya FJ, Huang H-P, Qiu Y et al (1997) Diabetes, defective pancreatic morphogenesis, and abnormal enteroendocrine differentiation in BETA2/NeuroD-deficient mice. Genes Dev 11:2323-2334

35. Wang H, Hagenfeldt-Johansson K, Otten LA, Gauthier BR, Herrera PL, Wollheim CB (2002) Experimental models of transcription factor-associated maturity-onset diabetes of the young. Diabetes 51(Suppl 3):S333-S342

36. Wang H, Maechler P, Antinozzi PA, Hagenfeldt KA, Wollheim CB (2000) Hepatocyte nuclear factor 4alpha regulates the expression of pancreatic beta-cell genes implicated in glucose metabolism and nutrient-induced insulin secretion. J Biol Chem 275:35953-35959

37. Thorens B (2001) GLUT2 in pancreatic and extra-pancreatic gluco-detection (review). Mol Membr Biol 18:265-273

38. Schuit F, De Vos A, Farfari S et al (1997) Metabolic fate of glucose in purified islet cells. Glucose-regulated anaplerosis in beta cells. J Biol Chem 272:18572-18579

39. Lu D, Mulder H, Zhao P et al (2002) 13C NMR isotopomer analysis reveals a connection between pyruvate cycling and glucose-stimulated insulin secretion (GSIS). Proc Natl Acad Sci USA 99:2708-2713

40. Matschinsky FM (1996) Banting Lecture 1995. A lesson in metabolic regulation inspired by the glucokinase glucose sensor paradigm. Diabetes 45:223-241

41. Zhang CY, Baffy G, Perret P et al (2001) Uncoupling protein-2 negatively regulates insulin secretion and is a major link between obesity, beta cell dysfunction, and type 2 diabetes. Cell 105:745755

42. Wang J, Silva JP, Gustafsson CM, Rustin P, Larsson NG (2001) Increased in vivo apoptosis in cells lacking mitochondrial DNA gene expression. Proc Natl Acad Sci USA 98:4038-4043

43. Clayton PT, Eaton S, Aynsley-Green A et al (2001) Hyperinsulinism in short-chain L-3-hydroxyacyl-CoA dehydrogenase deficiency reveals the importance of beta-oxidation in insulin secretion. J Clin Invest 108:457-465

44. Ishihara H, Wang H, Drewes LR, Wollheim CB (1999) Overexpression of monocarboxylate transporter and lactate dehydrogenase alters insulin secretory responses to pyruvate and lactate in beta cells. J Clin Invest 104:1621-1629

45. Sekine N, Cirulli V, Regazzi R et al (1994) Low lactate dehydrogenase and high mitochondrial glycerol phosphate dehydrogenase in pancreatic beta-cells. Potential role in nutrient sensing. J Biol Chem 269:4895-4902

46. Zhao L, Guo M, Matsuoka TA et al (2005) The islet beta cellenriched MafA activator is a key regulator of insulin gene transcription. J Biol Chem 280:11887-11894

47. Zhang C, Moriguchi T, Kajihara M et al (2005) MafA is a key regulator of glucose-stimulated insulin secretion. Mol Cell Biol 25:4969-4976

48. Samaras SE, Zhao L, Means A, Henderson E, Matsuoka TA, Stein R (2003) The islet beta cell-enriched RIPE3b1/Maf transcription factor regulates pdx-1 expression. J Biol Chem 278:12263-12270

49. Newgard CB (2002) While tinkering with the beta-cell... metabolic regulatory mechanisms and new therapeutic strategies: American Diabetes Association Lilly Lecture, 2001. Diabetes 51:3141-3150

50. Horvath A, Szabadkai G, Varnai P et al (1998) Voltage dependent calcium channels in adrenal glomerulosa cells and in insulin producing cells. Cell Calcium 23:33-42 